\title{
A Física de um Desinfector com Radiação UV-C
} The Physics of a Disinfector With UV-C Radiation

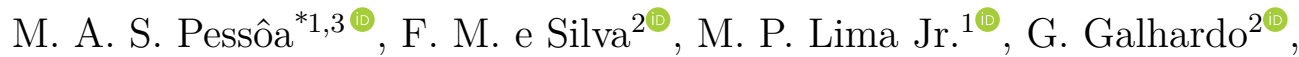 \\ P. H. M. Olyntho ${ }^{2 @}$, A. A. R. Neves \\ ${ }^{1}$ Universidade Federal do ABC (UFABC), Centro de Ciências Naturais e Humanas, Santo André, SP, Brasil. \\ ${ }^{2}$ Universidade Federal do ABC (UFABC), Centro de Engenharia, Modelagem e Ciências Sociais Aplicadas, Santo André, \\ SP, Brasil. \\ ${ }^{3}$ McGill University, Department of Physics, Montréal, QC, Canadá.
}

Recebido em 10 de junho de 2021. Revisado em 14 de junho de 2021. Aceito em 16 de junho de 2021.

\begin{abstract}
Neste artigo, discutimos a física envolvendo uma câmara de radiação ultravioleta-C (UV-C) utilizada para desinfecção de superfícies e objetos, no contexto da pandemia de COVID-19. Quando exposto à radiação UV-C, o RNA viral muda sua estrutura molecular num processo causado por uma realocação nas bases nitrogenadas, inativando o vírus e impedindo sua reprodução. Nós propomos a construção de uma câmara UV-C utilizando materiais acessíveis à população, com recursos de segurança. Também discutimos o processo de design na determinação da distância e tempo de exposição necessários para a dose de UV-C apropriada. Fatores teóricos que deixam o problema mais realista considerando-se a geometria do sistema também são utilizados. Experimentalmente, a lâmpada utilizada para o protótipo foi testada, obtendo-se uma potência na faixa do UV-C de $P_{u v}=171 \mu \mathrm{W}$, após correções. Os tempos de exposição foram então definidos, e variaram de 20-90 minutos, considerando-se distâncias de $5-36 \mathrm{~cm}$ dos objetos à lâmpada.
\end{abstract}

Palavras-chave: COVID-19, ultravioleta-C, Óptica, Desinfetante.

In this article, we discuss the physics involved in a ultraviolet-C (UV-C) radiation chamber used for disinfection of surfaces and objects, in the context of the COVID-19 pandemic. When exposed to UV-C radiation, viral RNA change its molecular structure, a process caused by a rearrangement in the nitrogenous basis, inactivating the virus, and preventing reproduction. We propose the construction of a UV-C chamber using materials that are accessible to the population, with security features. We also discuss the design process in determining the distance and exposition time needed for the appropriate UV-C dose. Theoretical correction factors are also used, in order to account for factors that make our approximations more realistic in terms of the geometry of the system. Experimentally, the lamp used for the prototype was tested, obtaining a power in UV-C range of $P_{u v}=171 \mu \mathrm{W}$, after corrections. Exposition times were then defined, ranging from 20-90 minutes, considering distances from 5-36 cm from the objects to the lamp.

Keyword: COVID-19, Ultraviolet-C, Optics, Disinfectant.

\section{Introdução}

A pandemia de COVID-19, doença causada pelo vírus SARS-CoV-2, já atingiu mais de 187 milhões de pessoas, com mais de 4 milhões de fatalidades, até a data de escrita deste artigo. Relatórios da Organização Mundial de Saúde (OMS), apontam uma concentração de casos e fatalidades nas regiões das Américas e da Europa [1, 2], assim como no sudeste asiático. Recentemente, novas variantes do vírus trouxeram novidades evolutivas que tornam-o mais transmissível e com capacidade de escape imune, tornando o controle da doença ainda mais difícil [3. A produção de vacinas eficazes na prevenção de mortes por COVID-19 ao final de 2020 foi um dos avanços mais significativos para trazer fim à pandemia [4] 6]. Entretanto, até que grandes parcelas da

\footnotetext{
*Endereço de correspondência: matheus.pessoa@mail.mcgill.ca
}

população sejam vacinadas, estratégias de isolamento social, utilização de máscaras e outros tipos de prevenção ainda são fundamentais. Especialmente no Brasil, onde a vacinação em massa ainda não ocorreu, é importante ter estratégias de combate que estejam à disposição da população.

As mutações associadas ao SARS-CoV-2, entretanto, são associadas à capacidade de infecção e interação com as células receptoras humanas. A morfologia do vírus continua sendo a mesma: um organismo parasita intracelular não-vivo que contém um envelope que protege material genético de RNA ou DNA em seu interior. Essa estrutura é sensível à influência de radiações em certos comprimentos de onda $(\lambda)$, como na faixa do ultravioleta-C (UV-C, na faixa $100 \mathrm{~nm}<\lambda<280 \mathrm{~nm}$ ) que são capazes de impedir a reprodução viral através da quebra de ligações na estrutura do material genético que ele carrega. Isso ocorre a partir da absorção das ondas de 
UV-C pelo RNA viral, que gera desarranjos de ligações moleculares e formações de novas menos eficientes na reprodução do vírus. Na estrutura viral, esse processo acontece principalmente entre duas bases adjacentes de uracila, originando dímeros, que são menos estáveis que suas ligações originais. Isso altera a efetividade na reprodução do vírus, assim como a sua inativação [7, 8]. Esse princípio vale também para as radiações UV-A e UV-B, porém de maneira muito mais ineficiente [9], podendo também gerar outros tipos de danos genéticos através da produção de espécies reativas de oxigênio que causam oxidação das bases. Relatamos neste trabalho aspectos didáticos de um desinfector utilizando radiação no UV-C, como estratégia de combate à pandemia. O UV-C é um potente aliado no combate a elementos patógenos e, portanto, seu uso é recomendável, mas deve-se tomar algumas precauções em suas utilizações, pois a luz UV-C pode causar complicações na saúde se não usada de forma correta.

A utilização de radiação UV-C com finalidade germicida é um tema de amplo estudo e aplicações no ultimo ano [10 13. No atual contexto do combate ao vírus SARS-CoV-2, as aplicações são alternativas úteis para a esterilização de contaminações de superfícies e reutilização de máscaras N95 [14-17]. Isso dada a eficácia demonstrada em estudos experimentais recentes, diminuindo significativamente a concentração de vírus em superfícies. A capacidade de filtragem e integridade estrutural da máscara também foi estudada, comprovandose significativa para exposições com energia por unidade de área de $120-950 \mathrm{~J} / \mathrm{cm}^{2}$ [18. Entretanto, para a inativação do vírus $\mathrm{SARS}-\mathrm{CoV}-2$, a dosagem de radiação é significativamente menor. Para um comprimento de onda $\lambda \approx 254 \mathrm{~nm}$, uma exposição de 60 a 70 segundos com uma irradiância de $\approx 17 \mathrm{~mW} / \mathrm{cm}^{2}$ resulta em aproximadamente $1 \mathrm{~J} / \mathrm{cm}^{2}[19]$.

Aplicações em processos de desinfecção, são fornecidos pela indústria em faixas de comprimento de onda de 254 nm [20], por meio de lâmpadas germicidas como as de baixa pressão livre de ozônio, possuem maior durabilidade em relação às lâmpadas de média pressão [21].

Para desativação do coronavírus, é necessária uma dosagem de radiação UV-C, que está associada à transmissão de energia nessa faixa de comprimento de onda pela lâmpada utilizada, o tempo de exposição e a distância entre a lâmpada e o objeto a ser irradiado, como será discutido posteriormente. Na literatura, encontram-se diferentes doses para desinfecção utilizando radiação UV-C. Essas doses, assim como o tempo de desinfecção, encontram-se na Tabela 11. para superfícies diversas.

Os efeitos da luz solar no homem, microorganismos e produtos químicos tornaram-se um assunto de grande interesse e experimentação no século XIX. Em 1814, Fraunhofer mapeou mais de 500 bandas de luz solar, algumas das quais estavam na região ultravioleta. As primeiras observações científicas dos efeitos germicidas da
Tabela 1: Doses e tempos de exposição para diversos materiais.

\begin{tabular}{lccc}
\hline Material & Dose $\left[\mathbf{J} / \mathbf{c m}^{2}\right]$ & Tempo & Referência \\
\hline $\begin{array}{l}\text { Dispositivos } \\
\text { eletrônicos de mão }\end{array}$ & 0.20 & $25-30 \mathrm{~s}$ & {$[22]$} \\
Smartphones & 0.06 & $2-5 \mathrm{~min}$ & {$[23]$} \\
Vidro e plástico & $0.30-0.60$ & $15-60 \mathrm{~s}$ & {$[24]$} \\
Smartphones & Indefinida & $10 \mathrm{~min}$ & {$[25]$} \\
Máscaras N95 & 0.10 & $2.3-8.2 \mathrm{~min}$ & {$[26]$} \\
Máscaras N95 & 1.00 & Indefinido & {$[27]$} \\
Endoscópios & 0.20 & $25-30 \mathrm{~s}$ & {$[28]$} \\
\hline
\end{tabular}

radiação ultravioleta começaram com Downes e Blunt (1877) [29], que relataram que as bactérias eram inativadas pela luz solar e descobriram que o espectro azulvioleta era o mais eficaz. 30 realizou a primeira análise rigorosa dos efeitos da luz ultravioleta. Na década de 1930 surgiu as primeiras aplicações de sistemas UV em hospitais para controlar infecções. Na década de 1950, já estava bem estabelecido que a irradiação UV era eficaz na desinfecção do ar e das superfícies, e novas aplicações de engenharia começaram a ser desenvolvidas 7 .

A lavagem das máscaras é desaconselhável devido à redução da hidrofobicidade e capacidade do eletreto filtrar o vírus, com indicação, portanto, de uso único 31. Com isso surge a necessidade de encontrar outros meios para desinfecção das máscaras e outros objetos. Para o combate ao vírus, encontramos câmaras e recipientes para desinfecção portátil com alto custo relativo e dependência de importação [32, ou alternativas do tipo faça-você-mesmo, majoritariamente em língua inglesa, e sem um sistema de segurança necessários à utilização 33. Além disso, a física por trás da desinfecção é desconhecida por grande parte dos usuários, que são instruídos apenas a posicionar objetos dentro de uma caixa, e selecionar um tempo específico de irradiação. Nesse artigo, discutiremos a física por trás do funcionamento de uma câmara de desinfecção, assim como a metodologia de investigação sobre como obter uma distância ótima do objeto em relação à lâmpada, assim como o processo de definição dos tempos de exposição.

Com objetivo de ajudar a sociedade no combate à COVID-19, conscientização científica sobre o método envolvido no processo de irradiação, e da necessidade de métodos alternativos para a desinfecção de materiais expostos ao vírus SARS-CoV-2, foi desenvolvida uma câmara para desinfecção de objetos caseiros: máscaras sapatos, embalagens de alimentos, produtos do mercado, relógios, roupas, dentre outros. A câmara também contará com um sistema inteligente voltado ao cuidado à saúde do usuário, e produção de manual de utilização. Este artigo foi desenvolvido por alguns estudantes membros do projeto BURN (desinfector inteligente de Baixo custo Utilizando Radiação No UV-C) que demonstraram interesse em compartilhar o conhecimento sobre a física presente no desenvolvimento do projeto. O proto- 
colo descrito por esse projeto é o mesmo utilizado atualmente por entidades hospitalares em outros países pela sua capacidade de desinfectar objetos e superfícies 34 e, portanto, válido para aplicações também no Brasil.

Para o desenvolvimento de um protótipo eficaz, é importante primeiramente encontrar o tempo de radiação necessário para a inativação do vírus, descrito em 2.1. Dada a natureza da emissão de lâmpadas germicidas, que acontece em vários comprimentos de onda, é necessário quantificar quanto da potência é irradiada na faixa do UV-C, tema discutido em 2.2 Em 2.3. discutese a uniformidade de irradiação dentro da câmara, com argumentos geométricos, e estima-se a quantidade de radiação que os pontos mais distantes da lâmpada recebem. Em 2.4 discute-se a construção dos protótipos em termos da caixa utilizada, assim como a seleção do sistema de iluminação por UV-C. Uma parte importante do protótipo é a proteção do usuário, essencial para a difusão do projeto em larga escala; esse sistema de controle inteligente e de segurança é discutido em 2.5 Em 3, apresentamos os resultados para as otimizações realizadas, e em 4 as conclusões do trabalho.

\section{Metodologia}

\subsection{Cálculo dos tempos exposição}

Para entender como funciona o processo de desinfecção de superfícies, podemos fazer uma comparação com um fenômeno físico do decaimento radioativo. Nesse fenômeno, um material radioativo emite partículas em função do tempo, de forma que a variação na massa $d M(t) / d t$, é proporcional à quantidade de massa num dado instante de tempo, $M(t)$. Podemos escrever a relação entre essas duas quantidades também atribuindo uma constante de decaimento $\alpha$ ao processo, de forma que,

$$
\frac{\mathrm{d} M(t)}{\mathrm{d} t}=-\alpha M(t)
$$

Essa é uma equação diferencial ordinária de primeira ordem, e separável, cuja nota solução é um decaimento exponencial descrito por,

$$
M(t)=M_{0} \mathrm{e}^{-\alpha t}
$$

onde utilizamos o fato de que a massa em um instante inicial é $M(0)=M_{0}$. A sobrevivência de microorganismos à ação UV-C, em função do tempo, $S(t)$, pode ser descrita de modo análogo a um decaimento exponencial [7],

$$
S(t)=\mathrm{e}^{-k D(t)},
$$

onde $k$ também é uma constante de decaimento, e a função $D(t)$ que determina a dose de radiação necessária para exterminação do vírus. A eliminação completa de vírus na superfície (processo de esterilização) ocorre para tempos infinitos de exposição à radiação, ou seja, quando $t \rightarrow \infty$. Para uma eliminação de parte significativa de material viral, definimos duas doses importantes, comumente conhecidas de $D_{90}$ e $D_{99}$, para as quais há eliminação de $90 \%$ e $99 \%$ da população de vírus, respectivamente. Essa dose está diretamente relacionada à potência da lâmpada utilizada no processo e ao tempo de exposição, como veremos logo abaixo.

Como uma primeira aproximação para o cálculo do tempo, podemos considerar a lâmpada como uma fonte pontual, uma vez que o comprimento de onda é da ordem de $10^{-7} \mathrm{~m}$ (centenas de nanômetros), comparado à dimensão física da lâmpada e das distâncias que serão utilizadas na construção da câmara de desinfecção aqui descrita. A propagação de ondas a partir de uma fonte pontual pode ser considerada, como uma frente de onda esférica pelo princípio de Huygens, e podemos considerar a propagação espacial sendo descrita em geral por um elemento de distância $d$, tal que $d^{2}=x^{2}+y^{2}+z^{2}$, em coordenadas esféricas. Nesse caso, a área coberta pelas ondas emitidas pela fonte pontual é tal que $\mathcal{A}=4 \pi d^{2}$, e a energia, ou potência $(P)$ carregada pela onda decai com o quadrado da distância, $\left(P \propto d^{-2}\right)$.

A irradiância $\left(I_{r}\right)$, é a média de energia por unidade de tempo, por unidade de área, transferida pela luz a uma superfície, de forma que $I_{r}=P / \mathcal{A}\left[\mathrm{W} / \mathrm{cm}^{2}\right]$. A dose de radiação à qual os objetos estão expostos é determinada pela irradiância em função do tempo, de modo que $D(t)=I_{r} t$. Reescrevendo a irradiância como o quociente da potência da lâmpada na faixa específica do UV-C pela área, têm-se,

$$
D(t)=\frac{P_{u v}}{4 \pi d^{2}} t
$$

sendo $d$ a distância entre a fonte e o objeto. Para desativação do coronavírus, é necessária a dosagem de radiação UV-C de $1 \mathrm{~J} / \mathrm{cm}^{2}$ [18], para a qual há aproximadamente $90 \%\left(D_{90}\right)$ de taxa de desinfecção. O tempo de exposição pode ser calculado por [7, 15],

$$
t=\frac{4 \pi D_{90} d^{2}}{P_{u v}}
$$

em segundos, assumindo uma propagação esférica da onda eletromagnética no espaço. Por essa razão, no projeto, deve-se determinar a distância entre a fonte e a substância ou objeto a ser desinfectado. Um desenho esquemático está apresentado na figura 1] representando a lâmpada UV-C, a frente de onda esférica propagante, e o comportamento como uma fonte pontual, cobrindo uma área proporcional ao quadrado da distância $d$ da superfície.

A equação 3 pode ser analisada linearmente tomandose o logaritmo dos dois lados. Dessa maneira,

$$
\ln S(t)=-k D(t)
$$

O coeficiente angular da reta é, $k D(t)$, de onde podese tirar a taxa $k$ de susceptibilidade à radiação $\mathrm{UV}$ $\mathrm{C}$, expressa em $\left[\mathrm{cm}^{2} / \mathrm{J}\right]$. O comportamento da função 
Irradiação por uma fonte pontual

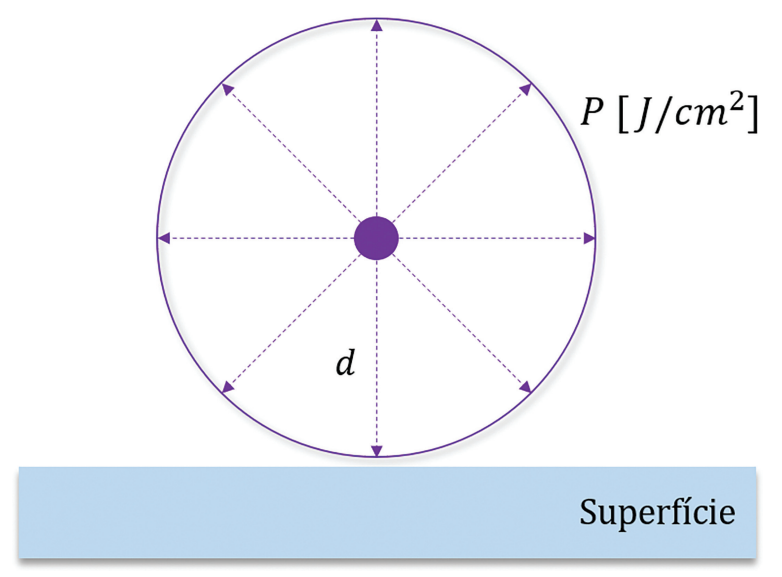

Figura 1: llustração da frente de iluminação de uma fonte pontual cuja superfície é proporcional a $d^{2}$.

$S(t)$ também pode contar com diferentes estágios, que são modelados também como decaimentos exponenciais. O nível de desinfecção $D_{90}$ corresponde a,

$$
D_{90}=\frac{-\ln (1,0-0,90)}{k}=\frac{2,3026}{k},
$$

enquanto o nível $D_{99}$ corresponde a,

$$
D_{99}=\frac{-\ln (1,00-0,99)}{k}=\frac{4,6051}{k} .
$$

A susceptibilidade $k$ é um fator próprio de cada sistema estudado, e deve ser determinado experimentalmente. Para os propósitos deste estudo, como não fizemos uma análise biológica da sobrevivência dos vírus em função do tempo, o fator não foi calculado.

\subsection{Estimando a potência da lâmpada no UV-C}

Lâmpadas que emitem radiação UV-C não emitem apenas nesta faixa, mas inclusive no visível. Por esta razão, podemos notar a coloração azulada ou violeta da lâmpada quando acesa. Mesmo tendo uma energia considerada alta dado o comprimento de onda em nanômetros, é possível barrá-la com alguns materiais, como o vidro comum, por exemplo. Essa é a razão pela qual lâmpadas $\mathrm{UV}-\mathrm{C}$, próprias para desinfecção de superfícies, são confeccionadas com a utilização de quartzo, em vez de vidro comum, uma vez que a absorção na faixa do UV-C é muito menor no quartzo do que no vidro. Lâmpadas UV-C que são confeccionadas com vidro comum e comercializadas como germicidas não terão esse efeito.

Sabendo-se do bloqueio, utilizamos um método para estimar a potência da lâmpada no UV-C utilizando uma lâmina de vidro de microscópio. O princípio é: os raios luminosos na faixa do visível conseguem atravessar o vidro, mas sabe-se que a radiação $\mathrm{UV}-\mathrm{C}$ é, em grande parte absorvida. Conforme confirmado em um

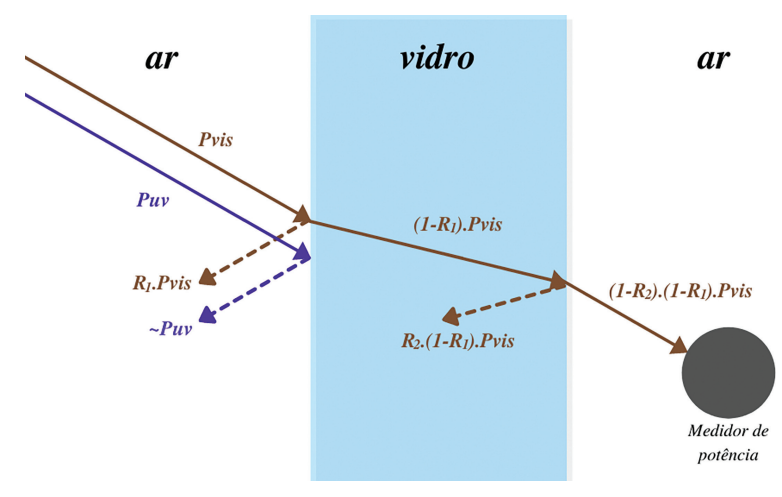

Figura 2: Desenho esquemático das grandezas envolvidas no cálculo do tempo necessário para desinfecção da superfície.

espectrômetro de UV-Vis para a mesma lâmina de vidro, há uma transmitância de apenas $0,15 \%$ da luz UV-C. Dessa forma, mede-se inicialmente, a potência da lâmpada sem nenhuma obstrução, com um medidor de potência, obtendo-se uma potência $P_{\text {tot }}$. Sabemos que nesta potência temos componentes visíveis que atravessarão o vidro, e partes em UV-C que serão absorvidas, indicando um novo valor no medidor de potência, $P_{\text {det }}$.

Para obtermos a potência no UV-C, devemos considerar os efeitos da reflexão das superfícies do vidro, veja a figura 2, Quando há introdução do vidro para medição, pode-se pensar nesse sistema óptico com duas interfaces: (i) Na primeira interface, dado o índice de refração do vidro teremos parte da potência incidente sendo refletida. Algo que não aconteceria caso não existisse o vidro, e portanto temos que levar este efeito em consideração. Depois dentro do vidro, a componente UV-C será quase que totalmente absorvida. (ii) Na última interface vidroar, teremos a última reflexão da componente visível, que deixa de ser capturada pelo detector. Por fim, o detector, com o vidro, não mede apenas a falta da componente do UV-C mas sim a perda da reflexão do visível pelo vidro. A potência total envolvida é a soma da parte visível da luz emitida com a parte no UV-C,

$$
P_{\mathrm{tot}}=P_{\mathrm{vis}}+P_{\mathrm{uv}} \text {. }
$$

Na primeira parte, quando o raio de luz é emitido pela lâmpada e encontra a superfície do vidro, uma parte do UV-C é refletida e absorvida. Considerando-se uma incidência normal a porcentagem de potência refletida na primeira interface, $R_{1}$ seria de,

$$
R_{1}=\left(\frac{n_{\mathrm{ar}}-n_{\mathrm{vid}}}{n_{\mathrm{ar}}+n_{\mathrm{vid}}}\right)^{2},
$$

onde $n_{\text {vid }}$ corresponde ao índice de refração do vidro, e $n_{\text {ar }}$ corresponde ao índice de refração do ar. Têm-se então uma quantidade $\left(1-R_{1}\right) P_{\text {tot }}$ sendo transmitida pelo vidro. Agora, a potência que sai da segunda interface (vidro-ar) até o detector corresponde a,

$$
P_{\text {det }}=\left(1-R_{2}\right)\left(1-R_{1}\right) P_{\mathrm{vis}},
$$


onde $R_{2}$ é determinado de forma análoga à apresentada na Eq. 10. Desta forma podemos determinar a potência no UV-C a partir da Eq. (9) como sendo,

$$
P_{\mathrm{uv}}=P_{\mathrm{tot}}-\frac{P_{\mathrm{det}}}{\left(1-R_{2}\right)\left(1-R_{1}\right)}
$$

Pode-se determinar o que chamamos de fator UV como sendo uma normalização da potência total pela potência emitida somente no UV-C. Assim, obtém-se,

$$
\text { Fator }_{\mathrm{uv}}=\frac{P_{\mathrm{uv}}}{P_{\mathrm{tot}}}=1-\frac{1}{\left(1-R_{2}\right)\left(1-R_{1}\right)} \frac{P_{\mathrm{det}}}{P_{\mathrm{tot}}}
$$

Esse fator é importante para uma estimativa da dose de irradiação que será utilizada na câmara, e deve ser determinado experimentalmente.

\subsection{Uniformidade de irradiação dentro da câmara}

No modelo em termos de potência, consideramos a propagação esférica e uniforme da lâmpada, uma vez que podemos tratá-la como uma fonte pontual. No caso real dentro da câmara, porém, há diferenças entre as intensidades luminosas que chegam em diferentes pontos da superfície, pois a lâmpada tem um formato cilíndrico. Por isso, precisamos determinar a uniformidade da luz no interior da câmara, pois com apenas uma lâmpada haverá regiões com maior intensidade e outras com menor intensidade de UV-C. Para uma desinfecção segura, precisamos garantir que a região de menor iluminação também receba a dose mínima recomendada para a desativação do coronavírus.

Para medir a influência geométrica da propagação na luz dentro da câmara, e a homogeneidade da iluminação, posicionamos o medidor OP-2/LM-2 UV, da marca Coherent com espectro de medição de $250 \mathrm{~nm}$ a 400 $\mathrm{nm}$ e capaz de medir potências entre $10 \mathrm{nW}$ e $30 \mathrm{~mW}$, em 9 localizações regulares, distantes $7 \mathrm{~cm}$ uma da outra, estando distantes $13,5 \mathrm{~cm}$ do plano horizontal da lâmpada. O desenho esquemático apresentado na figura 3 representa a disposição dos pontos em que as medições experimentais foram realizadas. Como a fonte (lâmpada de UV-C), é extensa e não pontual, vários pontos da lâmpada contribuem para a sensibilização de uma determinada região. Para entender como esta luz é distribuída, vamos utilizar um modelo conhecido 35, e publicado recentemente [14, ilustrado na figura 4. Neste modelo, considera-se a lâmpada como fonte extensa, porém sem levar em conta as reflexões pelas superfícies da câmara. Para isto, determina-se um parâmetro conhecido como fractional radiative irradiance (FRI), ou irradiância radioativa fracional, a partir do qual determina-se a fração de irradiância que chega em diferentes pontos da superfície. Na figura 4 , o ponto de interesse, por exemplo, é o que mais dista da lâmpada, e que precisa receber a mesma dose de radiação que os outros pontos para uma desinfecção eficaz. Seja $L$

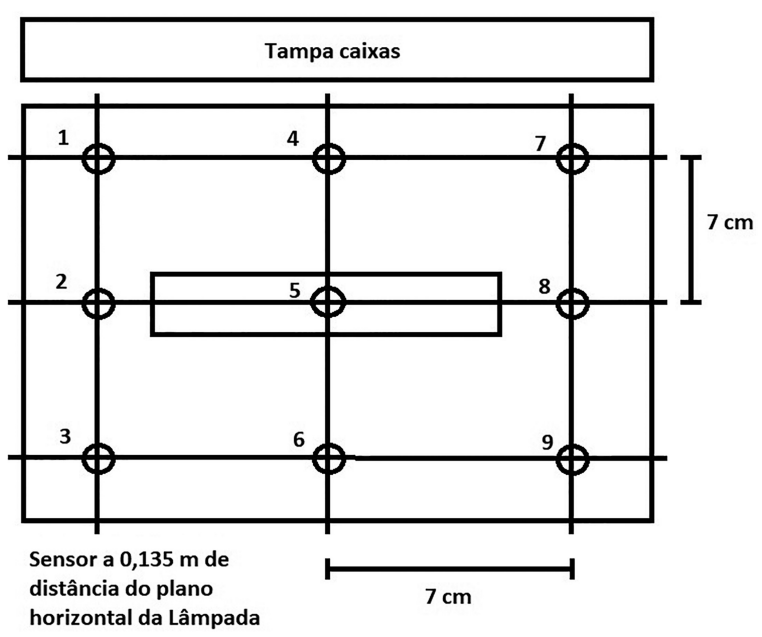

Figura 3: Desenho esquemático das localizações das medidas de potência.

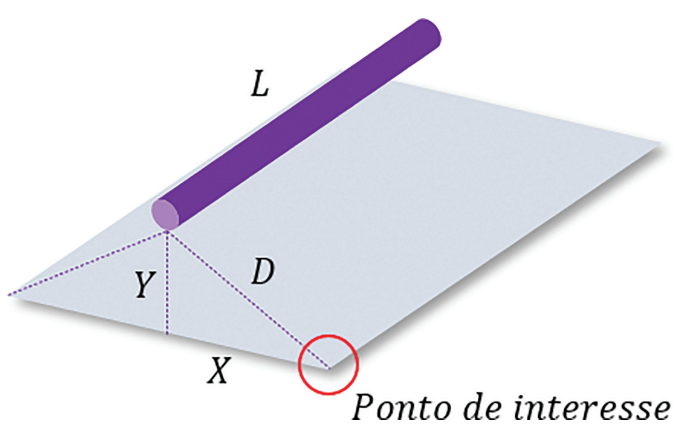

Figura 4: Geometria de iluminação de um plano por uma lâmpada linear, baseado no modelo proposto em [14].

o comprimento da lâmpada $(\mathrm{cm}), D$ é a distância $(\mathrm{cm})$ da lâmpada ao ponto de interesse, $R$ é o raio $(\mathrm{cm})$ do tubo UV. O fator FRI pode ser escrito como,

$$
\begin{aligned}
\mathrm{FRI}= & \frac{L}{\pi D}\left[\frac{R}{L} \arctan \left(\frac{L}{\sqrt{D^{2}-R^{2}}}\right)-\arctan \left(\sqrt{\frac{D-R}{D+R}}\right)\right. \\
& \left.+\frac{A-2 D / R}{\sqrt{A B}} \arctan \left(\sqrt{\frac{A(D-R)}{B(D+R)}}\right)\right]
\end{aligned}
$$

onde as abreviações correspondem a,

$$
\begin{aligned}
A R^{2} & =(R+D)^{2}+L^{2} \\
B R^{2} & =(R-D)^{2}+L^{2} \\
D & =\sqrt{X^{2}+Y^{2}}
\end{aligned}
$$

Da geometria do sistema, e calculando-se o fator FRI, podemos determinar a irradiância $\left(I_{r}\right)\left(\mathrm{W} / \mathrm{cm}^{2}\right)$. como

$$
I_{r}=\frac{P_{u v c}}{2 \pi R L} \mathrm{FRI}
$$

Os testes realizados são apresentados na figura 5 


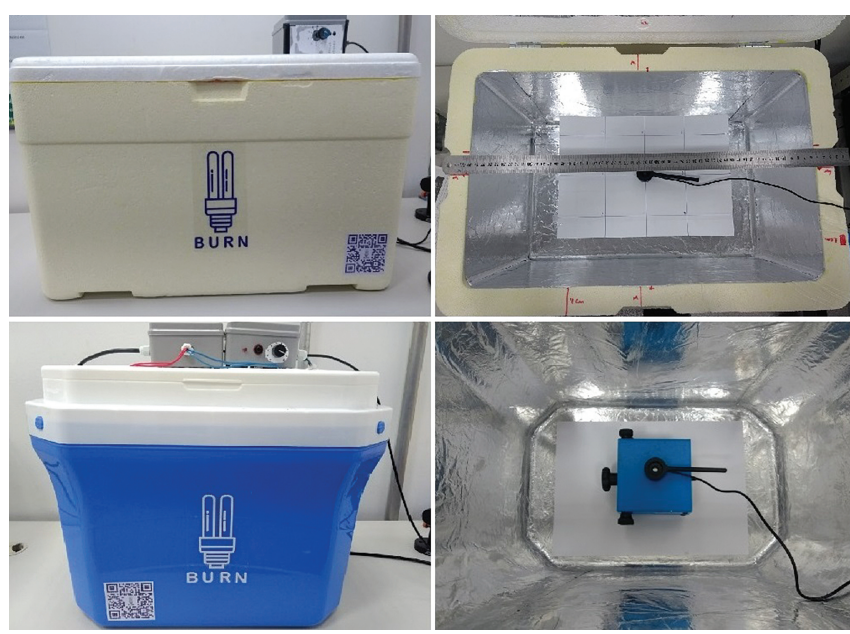

Figura 5: Superior da imagem: caixa de isopor e marcador de posição horizontal para sensor; Inferior da imagem: caixa de plástico e sensor sobre um macaco mecânico para variação de altura do sensor.

Tabela 2: Dimensões internas das caixas térmicas dos protótipos utilizados no projeto. As caixas térmicas de plástico, apresentam dimensões diferentes de profundidade, sendo $L_{f}=$ largura do fundo, $L_{T}=$ largura do topo, $P_{f}=$ profundidade do fundo, $P_{t}=$ profundidade do topo e $A=$ altura.

\begin{tabular}{lccc}
\hline Material & $L_{f}$ e $L_{T}(\mathbf{m m})$ & $A(\mathbf{m m})$ & $P_{f}$ e $P_{t}(\mathbf{m m})$ \\
\hline Isopor & 510 & 280 & 310 \\
Plástico & $390 / 420$ & 360 & $250 / 280$ \\
\hline
\end{tabular}

\subsection{Protótipo de câmara de desinfecção}

Para a câmara de desinfecção, realizamos a construção de protótipos de baixo custo, otimizando a eficiência na emissão de luz UV-C e avaliando a segurança na utilização do sistema inteligente de segurança e seleção das doses de radiação.

Como câmara de desinfecção, foram utilizadas dois tipos de caixas térmicas: uma opção de isopor com volume de 50 litros, para objetos maiores, e uma de plástico com maior portabilidade, de volume 42 litros. As dimensões de cada modelo são apresentadas na Tabela 2. A caixa foi revestida internamente com papel alumínio para melhor refletir a luz UV-C.

O sistema de desinfecção consiste numa lâmpada UV-C fixada internamente na tampa da câmara e no circuito de controle. Selecionamos a lâmpada UVC (Puritech HNS Linear G6T5, OSRAM) [36], que é de baixa pressão e sem produção de ozônio, e possui pico de radiação UV-C no comprimento de onda de aproximadamente em $254 \mathrm{~nm}$. Os dados técnicos da lâmpada são apresentados na Tabela 3

\subsection{Sistema de controle inteligente}

Para proteção contra a radiação UV-C, foi necessário a implementação de um controle eletrônico automatizado de baixo custo para ajuste de tempo e sistema de
Tabela 3: Lâmpada OSRAM, e $L_{\max }=$ comprimento máximo da lâmpada. A irradiação UV-C para o comprimento de onda de $253,7 \mathrm{~nm}$, foi medida a $1 \mathrm{~m}$ de distância, a $20^{\circ} \mathrm{C}$ de temperatura ambiente pelo fabricante.

\begin{tabular}{lccc}
\hline Modelo & $\begin{array}{c}\text { Potência } \\
\text { Total }(\mathbf{W})\end{array}$ & Soquete & $\boldsymbol{L}_{\text {max }}(\mathbf{m m})$ \\
\hline G6T5/OF & 6 & G5 & 226,3
\end{tabular}

segurança com desligamento automático. Esse sistema é importante em caso de abertura de tampa antes do término do processo de desinfecção, ou tentativa de utilização sem o fechamento da tampa da câmara. O sistema de desligamento automático é baseado nos diferentes tempos de exposição necessários para desativação de coronavírus em 90\%, conforme indicam as páginas do fabricante de produtos comerciais [37. O desligamento do sistema ocorre ao fim do tempo de exposição previamente selecionado, prevenindo os usuários de acidentes causados por exposição à luz UV-C e os seus riscos associados.

O sistema de controle de tempo inteligente implementado é baseado na configuração monoestável do circuíto integrado 555, que possui 8 pinos 38. Estes temporizadores são amplamente usados em várias aplicações, e podem ser substituídos por temporizadores mais sofisticados [39]. No circuito monoestável, o 555 funciona como um contador de tempo, que ao ser acionado por um botão de acionamento, leva a saída ao nível lógico alto, portanto a $5 \mathrm{VCC}$, permanecendo ligado por um tempo determinado pela relação de resistência $(r)$ e capacitância $(\mathrm{C})$, com desligamento automático após o ciclo. O tempo que a saída para acendimento da lâmpada permanece ligada, é calculado através da equação 19. com o tempo dado em segundos:

$$
T=1.1 R 5(C 1+C 2)
$$

O esquemático do circuito elétrico foi realizado com o programa EasyEDA (EasyEDA, versão 2020) e está apresentado na figura 6. O acionamento deste temporizador de tempo é realizado pelo botão (BT1), ligando Trigger (pino 2) ao negativo que inicia o ciclo de contagem de tempo, e acionando OUT (pino 3), com nível lógico alto ( $5 \mathrm{VCC})$, acionando o relê 1 que aciona a lâmpada UV-C. O resistor (R5), controla o tempo de carregamento dos capacitores (C1 e $\mathrm{C} 2$ ), que com carga igual 2/3 de tensão VCC, dispara o Threshold (pino 6), leva Out (pino 3), ao nível lógico baixo, enquanto Discharge (pino 7) descarrega os capacitores. Com o potenciômetro de 4,7 $\mathrm{M} \Omega$, e capacitores de 470 $\mu F$ cada em paralelo, totalizando $942 \mu \mathrm{F}$, obteremos o tempo que Out (pino 3), permanecerá ligado, $\operatorname{com} T=$ 4870, 14 s. Dividindo por 60, obtemos aproximadamente 81 minutos de tempo máximo com o circuito acionado. Para variação do tempo, foi utilizado um potenciômetro em R5, variando de 0 a 4,7 $\mathrm{M} \Omega$, e nos três circuitos montados chegamos em valores próximos a 100 minutos 


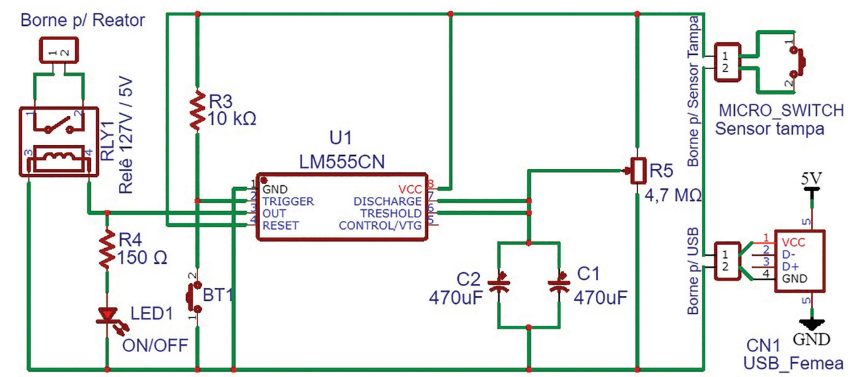

Figura 6: Esquema eletrônico do sistema inteligente de controle e segurança. Valores de componentes dimensionado para o tempo máximo de 90 minutos, necessário para desinfecção de objetos nas dimensões da câmara.

de tempo máximo, uma folga de segurança de 10 minutos acima dos 90 minutos desejados para o projeto.

Como forma de garantir a segurança dos usuários, um sensor de tampa assegura o fechamento da câmara para que não ocorra exposição do usuário, realizando o desligamento do circuito de alimentação $5 \mathrm{~V}$ que desliga a lâmpada e não permite sua utilização, até o posicionamento da tampa ser restabelecido. Esta configuração transforma o sistema passivo em uma ferramenta ativa, portanto inteligente, que permite o controle de tempo na dosagem de radiação $\mathrm{UV}-\mathrm{C}$, e sua utilização com segurança em qualquer ambiente. A alimentação do circuito eletrônico de 5 Vcc é realizada por cabo USB, e isolado através do acionamento de um relé, na parte esquerda do circuito, temos o acionamento elétrico com tensões de 127 V ou 220 V, para lâmpada UV-C e reator, com alimentação por plugue para $110 \mathrm{~V}$ e $220 \mathrm{~V}$.

\section{Resultados e Discussões}

\subsection{Fator de correção UV}

Utilizando os valores de refração da faixa de radiação ultravioleta no vidro $n_{\text {vid,uv }}=1,5528^{1}$ e do ar $n_{\mathrm{ar}}=1$ o valor obtido para a refletividade na equação f10 foi de aproximadamente $4,7 \%$. Dessa forma a intensidade transmitida para dentro do vidro seria de $\left(1-R_{1}\right) \times P_{\text {tot }}$. Vale lembrar que a potência total, sem o vidro era na verdade a combinação da soma das componentes visível e de UV. De maneira análoga, para a interface vidroar a interação envolve predominantemente luz visível na faixa do violeta, que possui um índice de refração de $n_{\text {vid,vio }}=1.5290$. A refletividade obtida nessa interação foi $R_{2}=4,4 \%$. Dessa forma, utilizando os valores de refletividade encontrados e os valores de $P_{\text {tot }}=206 \mu \mathrm{W}$ e $P_{\text {det }}=32 \mu \mathrm{W}$ obtidos experimentalmente, pode ser feita uma correção do Fator $_{\text {uv }}$, conforme a tabela 4 Nota-se que a diferença não é significativa entre as potências, e que o fator de correção tem uma diferença de $1 \%$.

1 https://refractiveindex.info/download/data/2017/schott_201701-20.pdf
Tabela 4: Dados experimentais medidos a $13,5 \mathrm{~cm}$ da lâmpada. As incertezas apresentadas são as incertezas do próprio instrumento, de $4 \%$.

\begin{tabular}{lcc}
\hline Variável & Sem correção & Com correção \\
\hline$P_{\text {tot }}$ & $(206 \pm 8) \mu \mathrm{W}$ & $206 \mu \mathrm{W}$ \\
$P_{\text {det }}$ & $(32 \pm 1) \mu \mathrm{W}$ & $32 \mu \mathrm{W}$ \\
$P_{\mathrm{uv}}$ & $(174 \pm 7) \mu \mathrm{W}$ & $171 \mu \mathrm{W}$ \\
Fator $_{\mathrm{uv}}$ & 0,84 & 0,83 \\
\hline
\end{tabular}

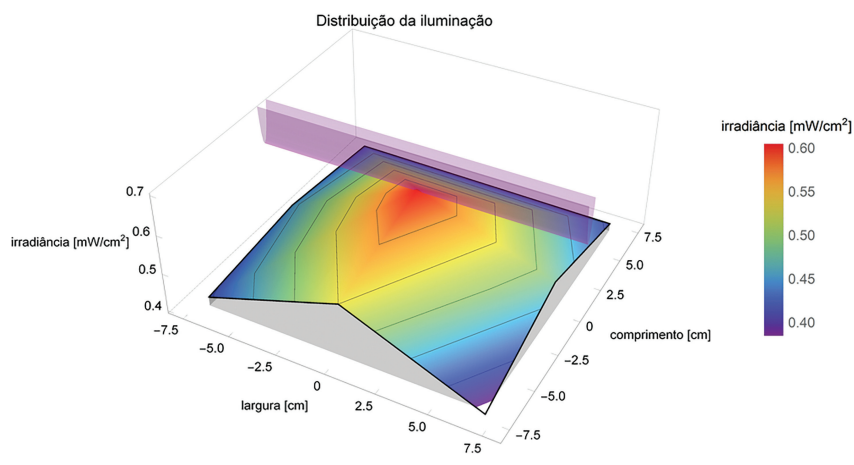

Figura 7: Medições experimentais para estudo da variação da Irradiância de UV-C em função das diferentes posições dentro da câmara. A lâmpada UV-C foi posicionada a $13,5 \mathrm{~cm}$ da superfície, e o medidor de potência utilizado para medir a irradiância foi colocado nas posições descritas na figura 3

\subsection{Distribuição de irradiação na câmara}

Efetuando medições de potência de acordo com a metodologia descrita na seção 2.3 com a lâmpada distante $13.5 \mathrm{~cm}$ do medidor de potência, obteve-se a distribuição espacial de irradiação apresentada na figura 7. Nota-se a maior concentração de radiação na região imediatamente abaixo da parte central da lâmpada, de $0.6 \pm 0.1 \mathrm{~mW} / \mathrm{cm}^{2}$. Nota-se uma menor irradiância nas quinas da caixa, de aproximadamente $0.4 \pm 0.1 \mathrm{~mW} / \mathrm{cm}^{2}$. Essas medições experimentais reforçam a necessidade de utilizar-se a dose de radiação $D_{90}$ baseando-se nos lugares onde irradiação é menor, de forma a garantir a desinfecção de toda a superfície.

Na figura 8, apresentamos medições de irradiância em função da distância da lâmpada. Os dados foram ajustados a duas curvas, representadas em azul e vermelho. A curva em azul é um ajuste do tipo $f(x)=a+\frac{b}{\left(x-x_{0}\right)^{2}}$, um decaimento conforme o quadrado da distância $x$, com $a, b$ e $x_{0}$ sendo constantes de ajuste. A curva em vermelho representa o ajuste conforme o tratamento descrito em (2.3), utilizando-se a equação (18). Notase que, dadas as dimensões da câmara e da lâmpada UV-C, o ajuste não apresenta divergências significativas em relação ao modelo mais simples.

\subsection{Protótipo versão final}

Após os testes laboratoriais detalhados em 2.2 e 2.3 . foi implementado um protótipo em sua versão final, buscando a otimização do processo de desinfecção e 


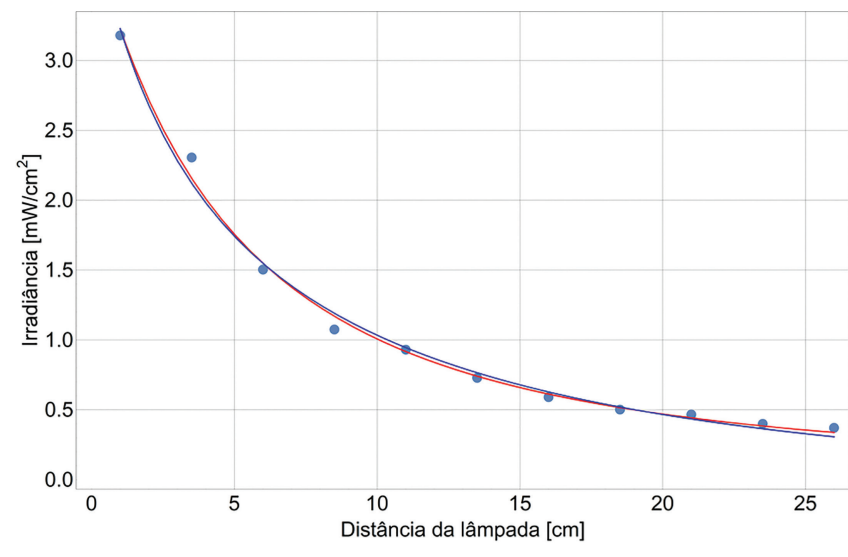

Figura 8: Ajuste da variação da irradiância em função da distancia para a lâmpada.
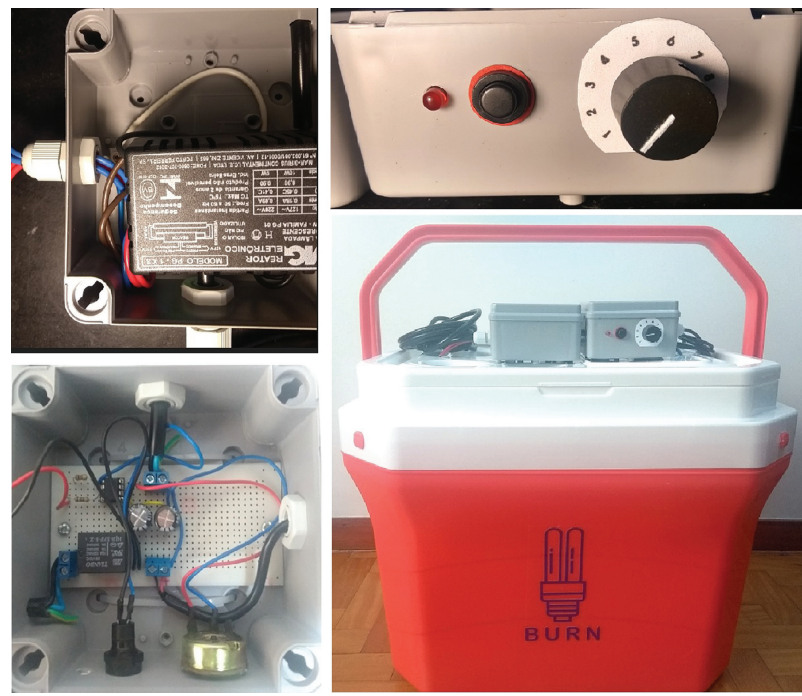

Figura 9: Protótipo em sua versão final. Esquerda superior temos a caixa de elétrica para o reator e entrada de alimentação $110 \mathrm{~V}$ ou $220 \mathrm{~V}$; inferior esquerda caixa do sistema eletrônico de controle inteligente; superior direita temos o painel de acionamento e seletor de tempo numerado; inferior direita temos o sistema completo em sua versão de plástico.

usabilidade da câmara de desinfecção. Agregando a melhoria de disposição dos componentes, implementação de componentes para proteção à entrada de água e poeira para as caixas de elétrica e eletrônica, definição das três alturas para objetos e confirmação dos tempos de exposição dos objetos à radiação pelo sistema de iluminação, levando em conta as dimensões de ambos modelos de caixas térmicas. Incluímos também uma marcação no potenciômetro numerado de 0 a 10, facilitando a seleção pelos usuários. O sistema em suas partes fundamentais e completo pode ser visualizado na figura 9 A câmara pode ser construída com caixas térmicas tanto de plástico como de isopor.

Para desinfecção, os objetos são posicionados em um dos três diferentes níveis, dependendo de suas dimensões,

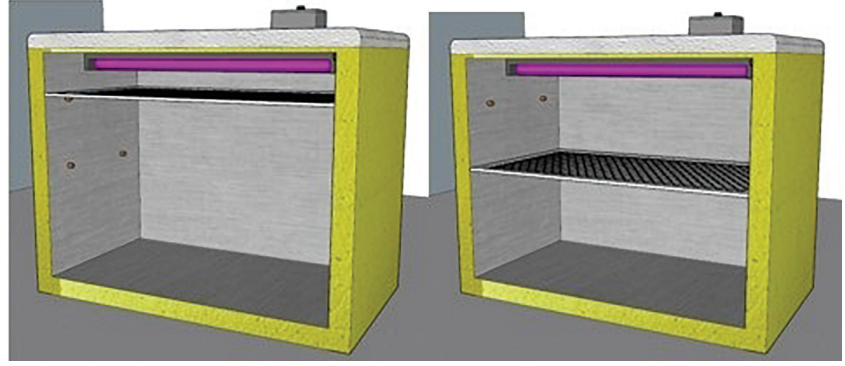

Figura 10: Três diferentes níveis para os objetos na câmara. Nível $1 \rightarrow 5 \mathrm{~cm}$ - Tempo para desinfecção de $90 \%$ da superfície: 20 minutos; Nível $2 \rightarrow 20 \mathrm{~cm}$ - Tempo para desinfecção de $90 \%$ da superfície: 50 minutos; Nível $3 \rightarrow 36 \mathrm{~cm}$ (Fundo da câmara) Tempo para desinfecção de $90 \%$ da superfície: 90 minutos.

Tabela 5: Distância e tempo de exposição para desinfecção de $90 \%$.

\begin{tabular}{lcc}
\hline $\begin{array}{l}\text { Distância (cm) } \\
\text { da lâmpada }\end{array}$ & $\begin{array}{r}\text { Tempo de } \\
\text { exposição }(\mathbf{m i n})\end{array}$ & Potenciômetro \\
\hline 5 & 20 & posição 3 \\
20 & 50 & posição 6 \\
36 (Fundo da câmara) & 90 & posição 10 \\
\hline
\end{tabular}

e então uma das posições do potenciômetro é selecionada para desligamento automático no tempo necessário para desinfecção.

A representação dos níveis e da câmara com o sistema de controle inteligente, foi ilustrada no software Sketchup (versão 2020, Trimble), e apresentado na figura 10 Na tabela 5 as distâncias da lâmpada ao objeto, e o tempo de exposição, assim como a posição para seleção no potenciômetro. O tempo de exposição foi calculado a partir de resultados experimentais da emissão da lâmpada UV-C.

\subsection{Testes laboratoriais do sistema}

Foram feitos testes de potência de lâmpada, como descrito em 2.2 e de distribuição da radiação dentro da câmara. Além dos dados da radiação, os testes aferiram o funcionamento do sistema para desligamento automático, proteção à exposição à radiação pelo usuário em caso de abertura da tampa antes do término do tempo previamente selecionado. Os testes de potência de lâmpada, foram realizados com a tampa fechada, nos modelos de plástico e isopor, variando-se a altura do sensor de luminosidade em relação à lâmpada no ponto central, e também em outras distribuições horizontais, simulando objetos de várias dimensões. Os tempos de exposição necessários para desinfecção de $90 \%$ da superfície a $5 \mathrm{~cm}, 20 \mathrm{~cm}$ e $36 \mathrm{~cm}$ da lâmpada são $5 \mathrm{~min}$, 20 min, e 90 min, respectivamente.

\section{Conclusões}

Neste trabalho, apresentamos um modelo de protótipo a ser utilizado no combate à pandemia de COVID-19, 
utilizando radiação no UV-C. Com base em referências da literatura, apresentadas na tabela 11 definiu-se a dose de radiação necessária para eliminação de $90 \%$ do vírus SARS-CoV-2 em superfícies como sendo de $D_{90}=1 \mathrm{~J} / \mathrm{cm}^{2}$. Essa dose serviu de base para o dimensionamento de uma caixa que contivesse uma lâmpada UV-C, assim como a definição de diferentes tempos de exposição. O protótipo foi construído com um sistema de controle e segurança inteligente. Experimentalmente, mediu-se a distribuição da irradiância em diferentes posições da câmara com um medidor de potência.

O sistema de desinfecção funciona de forma inteligente, com desligamento automático ao final do tempo selecionado, e também em caso de abertura de tampa. $\mathrm{O}$ revestimento interno evita a exposição de luz UV-C pelos usuários e contribui também para uma melhor distribuição de irradiação de luz UV-C dentro da câmara. Chegamos a uma melhor disposição dos componentes eletrônicos, com inclusão de indicador numérico para seleção de tempo, e proteção para o circuito elétrico e eletrônico, minimizando os riscos de acidentes, como derramamento de líquidos e poeira, aumentando a vida útil do sistema.

O projeto hoje se encontra aberto para realização de parcerias e colaborações com hospitais, empresas do ramo da saúde e institutos de pesquisa visando potencializar o alcance e o impacto dessa tecnologia. A divulgação dos manuais de montagem de maneira faça-você-mesmo nos repositórios Instructables 33. e Tecnologias Libres [40] garantindo a democratização do conhecimento científico e visando o cumprimento do papel de facilitador ao acesso do público geral de uma ferramenta de combate à contaminação pelo SARS-CoV-2.

Com a validação experimental da eficácia da câmara inteligente de desinfecção de SARS-CoV-2 por UV-C e com o aprofundamento teórico obtido na construção do protótipo e dos materiais de divulgação, o modelo base pode ser aprimorado com sistemas de controle mais completos e com uma maior gama de funções, além da substituição de determinados materiais e geometrias usadas na estrutura, com o objetivo de maximizar a área afetada pela radiação $\mathrm{UV}-\mathrm{C}$ e diminuir o tempo para a descontaminação. O projeto tem potencial de aprimoramentos futuros que possam permitir seu uso em ambientes controlados como hospitais e clínicas de saúde.

\section{Referências}

[1] https://www.who.int/publications/m/item/weekly-epi demiological-update-1-december-2020.

[2] https://apps.who.int/iris/handle/10665/338703.

[3] https://www.biorxiv.org/content/10.1101/2021.03.01.4 33466v1.full.pdf +html
[4] F.P. Polack, S.J. Thomas, N. Kitchin, J. Absalon, A. Gurtman, S. Lockhart, J.L. Perez, G.P. Marc, E.D. Moreira, C. Zerbini et al., N Engl J Med 383, 2603 (2020).

[5] Y. Zhang, G. Zeng, H. Pan, C. Li, Y. Hu, K. Chu, W. Han, Z. Chen, R. Tang, W. Yin et al., The Lancet Infectious Diseases 21, 149 (2021).

[6] F. Krammer, Journal of the American Academy of Dermatology 586, 516 (2020).

[7] W. Kowalski, Ultraviolet germicidal irradiation handbook: UVGI for air and surface disinfection (Springer science, Berlim, 2010).

[8] B. Filho, C. Antônio e C.D. Borges, Braz. J. Food Technol. 23, e2018321 (2020).

[9] G. Ronto, S. Gaspar, A. Fekete, T. Kerekgyarto, A. Berces e P. Grof, Adv Space Res 30, 1533 (2002).

[10] M.G. Strakhovskaya, A. Meerovich, A.N. Kuskov, S.A. Gonchuko e V.B. Loschenov, Laser Physics Letters 17, 093001 (2020).

[11] J. Hadi, M. Dunowska, S. Wu e G. Brightwell, Pathogens 9, 737 (2020)

[12] R. Quevedo-león, J.M. Bastías-Montes, T. EspinozaTellez, B. Ronceros, I. Balic e O. Muñoz, Scientia Agropecuaria 11, 257 (2020).

[13] M. Heßling, K. Hönes, P. Vatter e C. Lingenfelder, GMS Hyg Infect Control. 15, 1 (2020).

[14] M. Purschke, M. Elsamaloty, J.P. Wilde, N. Starr, R.R. Anderson, W.A. Farinelli, F.H. Sakamoto, M. Tung, J. Tam, L. Hesselink et al., Applied Optics 59, 7585.

[15] D. Mills, D.A. Harnish, C. Lawrence, M. SandovalPowers e B.K. Heimbuch, Am J Infect Control. 46, e49 (2018).

[16] K. O'Hearn, S. Gertsman, M. Sampson, R. Webster, A. Tsampalieros, R. Ng, J. Gibson, A.T. Lobos, N. Acharya, A. Agarwal et al. Journal of Hospital Infection 106, 163 (2020).

[17] K. Seresirikachorn, V. Phoophiboon, T. Chobarporn, K. Tiankanon, S. Aeumjaturapat, S. Chusakul, K. Snidvongs, Infect Control Hosp Epidemiol 42, 25 (2021).

[18] W.G. Lindsley, S.B. Martin Jr, R.E. Thewlis, K. Sarkisian, J.O. Nwoko, K.R. Mead e J.D. Noti, J Occup Environ Hyg 12, 509 (2015).

[19] I.H. Hamzavi, A.B. Lyons, I. Kohli, S. Narla, A. ParksMiller, J.M. Gelfand, H.W. Lim e D.M. Ozog, J Am Acad Dermatol 82, 1511 (2020).

[20] https://www.uv-el.de/en/uv-technology/uv-disinfectio n/, acesso em maio de 2020.

[21] https://www.uv-el.de/en/uv-technology/types-of-uvlamps/, acesso em maio de 2020.

[22] S. Cremers-Pijpers, C. Rossum, M. Dautzenberg, H. Wertheim, A. Tostmann e J. Hopmana, Infection Prevention in Practice 3, 100133 (2021).

[23] M.T. Lieberman, C.M. Madden, E.J. Ma e J.G. Fox, J Am Assoc Lab Anim Sci. 57, 24 (2018).

[24] R.L. Wallace, M. Ouellette e J. Jean, J Appl Microbiol 127, 586 (2019).

[25] G. Spataro, S. Burgassi, G. Cevenini, N. Nante, M. Tani e G. Messina, European Journal of Public Health 27, ckx186.156 (2017). 
[26] E.M. Fisher e R.E. Shaffer, J Appl Microbiol. 110, 287 (2011).

[27] A. Su, S.M. Grist, A. Geldert, A. Gopal e A.E. Herr, medRxiv (2020).

[28] S.A. Rudhart, F. Günther, L. Dapper, K. Thangavelu, F. Gehrt, P. Stankovic, T. Wilhelm, T. Guenzel, B.A. Stuck, S. Hoch, Eur Arch Otorhinolaryngol. 277, 2363 (2020)

[29] A.M.W. Downing e T.P. Blunt, Proc. R. Soc. Lond. 26 488 (1877).

[30] N.R. Finsen, Mitt. Finsen Inst. 1, 8 (1900).

[31] https://tinyurl.com/efphaxnf, acesso em maio de 2020.

[32] https://pt.dhgate.com/product/the-latest-uvc- \steril ization-box-shoe-box/526230172. \html?skuid=6979156 16058335232\#seo=WAP, acesso em maio de 2020.

[33] https://tinyurl.com/5sze4k5c, acesso em maio de 2020.

[34] https://bit.ly/2UA7u2P

[35] W.J. Kowalski e W.P. Bahnfleth, em: American Society of Heating, Refrigeration and Air Conditioning Engineers, Inc. (Minneapolis, 2000).

[36] https://www.osram.us/pia/products/discharge/ $\backslash p 00$ 1_pia_product_detail_6.jsp, acesso em maio de 2020.

[37] https://www.uv-light.co.uk/coronavirus/, acesso em maio de 2020.

[38] https://eletronworld.com.br/eletronica/o-ci-555/ acesso em maio de 2020 .

[39] R. Hessel, C.S. de Oliveira, G.A. Santarine e D.R. Vollet, Revista Brasileira de Ensino de Física 30, 1501 (2008).

[40] https://tinyurl.com/2kvzbr95, acesso em maio de 2020. 